\title{
What Enhances Language Learners' Motivation? - High school English learners' motivation from the perspective of Self-Determination Theory -
}

\section{廣森友人（ひろもり ともひと） 北海道大学}

This study aims to validate the applicability of Self-Determination Theory (SDT, hereafter), one of the well-developed motivation theories in psychology, to the study of EFL learner motivation. In addition, with the examination of motivating factors, or psychological needs as precursors of motivation, implications for educational practice will be considered with reference to how to motivate learners.

The application of SDT was motivated by the gap between what the motivation research has been studying and what EFL practitioners want to know. The focus of much language learning motivation research so far has been placed either on the motivational constructs themselves or on the relationships between language learning motivation and linguistic or non-linguistic outcomes, whereas language educators have been expecting the motivation research to provide strategies to motivate their students, i.e., "motivating factors" that they can foster to motivate language learners. Research needs to address this concern, and SDT has the potential to bridge the gap.

SDT is a theory of human motivation concerned with the development and functioning of personality within social contexts. In this theory, what are called basic psychological needs are regarded as the motivating factors for human development and functioning. They are innate, universal, and essential for health and well-being, which means that basic psychological needs are a natural

JALT Journal, Vol. 25, No. 2, November, 2003 
aspect of human beings that apply to all people, regardless of gender, group, or culture. Deci and Ryan (1985) postulate three psychological needs (the needs for autonomy, competence, and relatedness) as motivating factors which influence human motivation. It is hypothesized that if these psychological needs are met, intrinsic motivation will be enhanced, while, on the other hand, if they are not met, intrinsic motivation will be undermined.

The study reported here consists of several parts. First, the validities of two scales developed in a pilot study were examined. A psychological needs scale was designed to assess the constructs of autonomy, competence, and relatedness, while a language learning motivation scale was designed to assess the constructs of five types of motivation (i.e., intrinsic motivation, identified regulation, introjected regulation, external regulation, and amotivation). These two scales were administered to 275 first-year high school students. Using exploratory factor analysis, the construct structures were verified. Overall, results showed that the construct validities of these two scales were supported and good reliability coefficients were obtained. Based on the results of exploratory factor analysis, confirmatory tests of the factor structures were carried out, using confirmatory factor analysis. Results generally provided confirming evidence for the factorial structures of these two scales.

Second, a covariance structure analysis, alternatively known as Structural Equation Modeling (SEM) was used to explain the degrees of causal effect from the three psychological needs to several types of motivation. The SEM solution showed the following results: (a) learners' perceptions of their own selfcompetence had a strong influence on their motivation, (b) in order to enhance intrinsic motivation, the need for relatedness should be fulfilled, and (c) a desire for an autonomous climate in the classroom might affect motivation indirectly through learners' perceptions of being "competent."

Some educational implications were obtained. Among them, what seemed most important was that targeting each learner's perceptions of competence and the development of each type of motivation could be a good strategy for effectively enhancing his/her self-determined forms of motivation (i.e., intrinsic motivation) in school settings.

Since the act or phenomenon of motivating language learners needs synthesis in cognition and affect, studies like this current study are informative. They clarify "what" enhances language learners' motivation and "how" language learners' motivation is enhanced. Such a study offers a useful viewpoint when considering the English educational activities in a classroom because, if motivating factors are made known, it will become a precious source of information for educators. As a result, practitioners are better able to make judgments about motivating strategies in everyday classroom activities. Furthermore, it will also be helpful in providing counseling-advice to various types of language learners. 
本稿は、学習者の動機づけが「何によって高まるのか」を自己決定理論の枠組みから考 察したものである。予備調査を通じて作成された2つの尺度を用い、英語学習における心 理的欲求と動機づけの各タイプの関係が検討された。その結果、(1)学習者の有能性の認 知は、動機づけに対して強い影響を与えていること、(2)内発的動機づけを高めるには、 他者との関係性の欲求が満たされる必要があること、(3)教室での英語活動に対して、自 律的な風土に対する欲求は、有能性の認知を介して間接的に動機づけに影響を与える可能 性があることが示された。

学習者を動機づけるという行為、あるいは現象は、認知的・情意的な総合性を持つものであ る。学習における動機づけ要因の解明は、日常の教室活動において、教育者が学習過程のどの 部分に働きかけたらよいかを教えてくれる貴重な情報源になるものと思われる。

それまでの外国語教育に関する動機づけ研究は、その構成概念の理解や学 習成果との相関研究に焦点が当てられてきた。しかし、実際の教育活動を 進める上でより重要となってくることは、このような動機づけが「何によつ て高められるのか」を明らかにすることである。したがって本研究では、主として社 会心理学の研究分野で発展してきた内発的動機づけのパラダイムー自己決定理論 ( Self-Determination Theory）－を援用し、英語学習における学習者の動機づけを高め る要因について検討する。

\section{これまでの動機づけ研究}

外国語教育に限らず教育活動一般において、学習者の持つ動機づけが果た す重要性については、これまで多くの研究者によって指摘されてきた。例えば、 McCombs（1998）は学習に対する動機づけは学習の成否などを占う上で中心的な 役割を果たしていると述べており、第二言語習得の研究文脈でもE1lis (1994) をは じめ、近年ではDörnyei (1999) やCohen and Dörnyei (2002) によって、動機づけの 重要性が繰り返し指摘されている。

このような背景から、これまでさまざまな側面から動機づけに関する研究が数多 く行なわれてきたが、そこでの研究成果が実際の教室における英語教育活動に十分 に生かされてきたかといえば、必ずしもそうではなかった（山森、磯田、廣森、田辺、 2002）。著者はその原因の一つが、動機づけ研究が目指す研究対象と教育者の関心 対象との間における「溝」に大きく起因するものと考える。

これまでの動機づけ研究は、主として「動機づけ」という構成概念の記述・説明を目 指してきた (Chen, 1999; Dörnyei, 1990; Schmidt, Boraie, \& Kassabgy, 1996)。そこでは質 問紙調査などにより、学習者が「外国語を学ぶ“理由”」を明らかにするという試みが なされてきた。しかし、とりわけ日本の中学、高校などにおける外国語 (英語) 教育を考 える時、教育者は学習者がどんな理由で英語を学んでいようとも、それをどうにか教え なければならないという現実がある。つまり、教育者にとつては、どうすれば学習者を 効果的に動機づけられるのか、あるいは学習者を動機づける要因にはどのようなもの があるのか、ということを明らかにすることが主要な関心事なのである。

本研究ではこのような溝を埋める一つの試みとして、近年、動機づけ研究の理論的 枠組みとして注目を集めている自己決定理論の外国語教育への援用について検討す る。このような理論を援用することは、教室における学習者の学習活動の実態を反映 した動機づけ研究を可能とし、真に教育的示唆に富む研究を可能にするものと考え 
る。したがって、以下ではまず自己決定理論による動機づけについて触れ、その後、こ の理論と外国語学習との関連について考察する。

\section{自己決定理論による動機づけ}

1970年代以降、主として社会心理学の研究文脈ではDeci and Ryan（1985）などに よって「自己決定理論」(Self-Determination Theory; 以下ではSDTとする) というも のが提唱されてきた。これは人が当該の活動に対して、とりわけ内発的に動機づけ られるそのプロセスに注目した理論であり、そこでは次のようなモデルが想定されて いる。

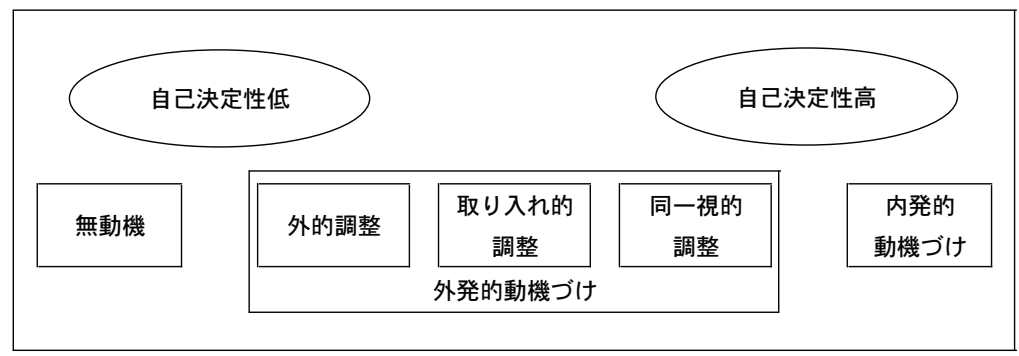

図1: 自己決定理論による連続体としての動機づけ

(Ryan \& Deci, 2002: 16を一部修正)

SDTによる内発的動機づけ（intrinsic motivation）とは人間に生得的に備わっている ものであり、自己決定された動機づけのプロトタイプとして概念化されている。また、 これまで多くの研究において、外発的動機づけは全く自律性がないもの、つまり内発 的動機づけとは相対するものとして捉えられてきた (Deci, 1975; Harter, 1981)。それに 対し、SDTでは外発的に動機づけられている行動であっても、内面化 (identification) と統合（internalization）の過程を通して自己決定的になる場合もあるとし、自己決定の 度合いに基づいてそれを3つに分類した（Deci \& Ryan, 1985, 2002）。

最も自己決定の程度の低い外発的動機づけは外的調整（external regulation）であ り、この段階では報酬などの外的圧力によって、行動が調整されている。このタイプの 動機づけは、「単位をとらないと夕゙メだから勉強する」「親に叱られないために勉強す る」場合などが挙げられる。取り入れ的調整（introjected regulation）は自己価值を維 持するなど自尊心に関連したものであり、行動は内的圧力によって調整されている。 しかし、「他の人にすごいと思わせたい」「恥をかくのを避けたい」など、活動はあくま でも外的な因果として位置づけられる。行動の内面化と統合が進み、自己決定のかな り高い段階が同一視的調整（identified regulation）である。この段階では、行動を個 人的に重要なものとして受容し、その価值を認めた上で行動を調整しており (つまり、 内的圧力）、活動は内的な因果として位置づけられている。このタイプの動機づけに は、「教師になりたいから勉強する」「自分がそうしたいから」などが挙げられる。さら に、内発的にも外発的にも動機づけられていない状態は無動機 (amotivation) の状態 とされる。 
SDTではこのような動機づけの各タイプに加えて、動機づけの先行要因、つまり これらの動機づけを高める要因 (motivating factors) というものを想定している。 それらは人間の生理的欲求とは区別される、3つの「心理的欲求」(psychological needs）であり、所与の活動において自分自身がより自己決定的でありたいという自律 性の欲求、自身がより有能でありたいという有能性の欲求、他者との人間関係がより 友好的でありたいという関係性の欲求という3つの欲求が含まれる。SDTではこれら の変数が心理的な媒介変数として位置づけられ、所与の外的事象がどのように認知 されるかによって、のちの動機づけに影響を与えると仮定している。

そこで本研究では、以上に述べた点を鑑み、自律性・有能性・関係性という心理 的欲求と動機づけの関係に焦点をあて、英語学習における動機づけが高まる際にこ のような動機づけ要因がどんな役割を果たすのかについて検討する。

\section{自己決定理論と外国語学習}

第二言語習得におけるこれまでの動機づけ研究は、Gardnerや彼の同僚らによ る一連の研究がその大勢を占めてきた (Gardner, 1985; Gardner \& Lambert, 1972; Gardner \& MacIntyre, 1993）。そこでの研究が基盤にもつ代表的な理論は、Gardner and Lambert (1972) に代表される動機づけの二分類 (「統合的志向性（integrative orientation）」と「道具的志向性（instrumental orientation）」）である。しかし、90年代 以降の外国語学習における動機づけ研究では、教育心理学や認知心理学などの関連 諸分野での研究成果を積極的に取り入れていこうとする気運が高まった (Crookes \& Schmidt, 1991; Oxford \& Shearin, 1994）。そのような中、特に外国語学習における自 律と内発的動機づけのもつ潜在的な役割については、とりわけ研究者の関心が集め られた。例えば、Ehrman（1996）では内発的動機づけが自己効力感や言語使用のみ ならず、スピーキングやライティングの熟達度とも正の相関を持つことが示された。ま た、Tachibana, Matsukawa, and Zhong (1996) は日本人英語学習者の英語に対する関 心が、内発的動機づけやより良い成績を取ろうとする態度を強めることを明らかにし た。

しかし、これらの研究は動機づけをあくまでも内発か外発かという2項対立的に捉 えており、「内発＝良い状態」「外発＝悪い状態（あるいは好ましくない状態）」という 図式を暗黙のうちに想定してきた。ところが、実際の教室場面に目を転じると、そこに は「高校／大学に合格するため」「就職のため」「教師や他の生徒に良い生徒だと思 われたいから」など、さまざまな動機づけをもつ学習者が存在することに気づく。従 来の動機づけの枠組みでは、これらはすべて「外発的動機づけ」に分類されるもので あったが、学習者の実態に即した動機づけ研究を進めようと思えば、これまで以上に 外発的動機づけのもつ意義についても積極的に認めていく必要があると考える。

本研究で用いるSDTは内発/外発の2分類ではなく、図1にみられるように、自己決 定 (つまり、自分の欲求の充足を自ら自由に選択すること) の度合いにより動機づけを 細分化し、動機づけの各タイプを連続体をなすものとして想定している。このような 枠組みを用い、動機づけを細分化し、動機づけ要因 (ここでは、心理的欲求) との関 連を検討することは、学習者を段階的に適応的な動機づけへと導くための教育的視 座を提供する上で、非常に重要だと考える。各動機づけの夕イプを詳細に検討するこ とは、学習者個々に対してより効果的な教育的介入をも可能とするであろう。したがつ て、SDTを援用することは非常に有益であり、これまでとは異なった視点から外国語 学習における動機づけについて検討することを可能にするものと考える。 


\section{調查}

\section{研究日的}

自己決定理論 (SDT) の枠組夕から、教室における英語教育場面において、自律性 ・有能性・関係性の各変数がごのように機能しているのか、つまり英語学習における 動機づけに対してどのような影響を与えているのかを明らかにし、日本の英語教育場 面へのSDTの適用可能性を検討する。

具体的には、3つの心理的欲求と動機づけの各夕イプに関する尺度を作成し、心 理的欲求から動機づけへの影響について検討する。

\section{調查内容}

本研究では、以下の2つの尺度が用いられた。

\section{英語学習における心理的欲求尺度}

英語教育の分野においてはこれまで、SDTに基づいて英語学習における心理的 欲求の尺度開発が行なわれたことはない。したがって、尺度の作成にあたっては、 SDTを対人関係や職場などの研究分野に応用した先行研究 (Ryan \& Deci, 2000な ぞ）を参考として予備調查を行い、3変数（自律性・有能性・関係性）のそれぞれにつ いて各4項目ずつ、合計12項目からなる尺度を作成した。

\section{英語学習における動機づけ尺度}

動機づけに関しても、同様にSDTに基づいて行なわれた先行研究 (Noels, Pelletier, Clement, \& Vallerand, 2000など) を参考とし、日本での英語教育場面を想定して、5つ の下位尺度（内発的動機づけ、同一視的調整、取り入れ的調整、外的調整、無動機） について各3項目ずつ、合計15項目の尺度を予備調査を通じて作成した。

なお、心理的欲求尺度、動機づけ尺度の評定はともに、「全然ああるいはほとんど 当てはまりません（1点）」から「常に、あるいはかなり当てはまります（5点）」までの 5件法で回答を求めた。

\section{被調查者と調查時期}

本研究の被調查者は北海道内の公立高校に在籍する高校 1 年生 275 名 (男子 128名、女子147名) であり、予備調査とは異なる集団である。なお、調査は2002年7月 から8月にかけて行なわれた。

\section{調查手続き}

被調査者の評定は各教室内で集団的に実施された。その際、社会的望ましさなど によるバイアスを考慮して、調査結果は集団データとして処理されること、また学校 での成績には一切関係しないことが説明された。

\section{分析方法}

分析にあたっては、記述統計量の算出や探索的因子分析などにはSPSS Base10.0Jが、 検証的因子分析や構造方程式モデリングにはAmos 4.0がそれぞれ用いられた。 


\section{結果と考察 \\ 心理的欲求尺度の分析結果}

尺度における偏り、および分散を検討した結果、いくつかの項目において正規分布 を逸脱していると思われる分布が見られた。しかし、項目ごとの平均値は最小で2.3、 最大で3.7と極端な偏りを示した項目、あるいは天井効果・床効果を示した項目は見 られなかったため、のちの分析には全12項目すべてを利用した。

次に、尺度に対する回答を探索的因子分析（最尤法、プロマックス回転）に投じた。 カイ2乗検定による適合度の高さ、パターン行列の解釈のしやすさなどから、最終的に、 先に仮定された 3 因子モデルを採択した。その後、採択されたモデルに対して解の妥当 性を検証するため、最尤法による検証的因子分析を行った。各尺度項目の平均、標準 偏差、探索的因子分析の結果 (パターン行列)、ならびに検証的因子分析の結果 (因子 間相関)について表1に示す。

表 $1:$ 心理的欲求尺度に関する探索的因子分析 (パターン行列) と検証的因子分析 (因子間相関) の結果

\begin{tabular}{cccccc}
\hline \multicolumn{1}{c}{ 質問項目 } & 自律性 & 関係性 & 有能性 & 共通性 & $\begin{array}{c}\text { 平均 } \\
\text { (標準偏差) }\end{array}$ \\
\hline 第1因子 $(\alpha=.75)$ & & & & & \\
\hline 自律1 (自分の意見は重要視されている) & $\mathbf{0 . 5 5}$ & 0.07 & -0.01 & 0.31 & $2.3(0.9)$ \\
自律2 (どんな兔強がしたいか意見を言える) & $\mathbf{0 . 6 3}$ & 0.07 & 0.04 & 0.44 & $2.3(1.0)$ \\
自律3 (勉強の仕方を決められる) & $\mathbf{0 . 8 1}$ & -0.11 & -0.01 & 0.64 & $2.4(0.9)$ \\
自律4 (選択肢が与えられている) & $\mathbf{0 . 5 0}$ & 0.03 & -0.14 & 0.21 & $2.6(0.9)$ \\
\hline 第2因子 $(\alpha=.76)$ & & & & & \\
\hline 関係1 (友達は私のことを気にかけてくれる) & -0.07 & $\mathbf{0 . 6 8}$ & 0.09 & 0.46 & $3.3(0.9)$ \\
関係2 (授業中は周りの友達とうまくやれている) & 0.07 & $\mathbf{0 . 5 9}$ & 0.06 & 0.37 & $3.4(1.1)$ \\
関係3 (一緒にいる友達を本当の友達だと感じる) & 0.09 & $\mathbf{0 . 5 2}$ & -0.04 & 0.29 & $3.0(1.0)$ \\
関係4 (クラスの友達はとても親切だと思う) & -0.02 & $\mathbf{0 . 7 8}$ & -0.10 & 0.62 & $3.7(0.9)$ \\
\hline 第3因子 $(\alpha=.74)$ & & & & & \\
\hline 有能1 (英語はできないと思う) 反転項目 & -0.07 & 0.01 & $\mathbf{0 . 8 1}$ & 0.61 & $2.6(1.0)$ \\
有能2 (英語ができるとは感じない) 反転項目 & -0.09 & -0.01 & $\mathbf{0 . 7 1}$ & 0.45 & $2.6(1.0)$ \\
有能3 (英語はよい成績が取れると思う) & 0.33 & 0.03 & $\mathbf{0 . 4 6}$ & 0.46 & $2.3(0.9)$ \\
\hline 因子間相関 第1因子 (自律性) & 1.00 & & & & \\
第2因子 (関係性) & 0.09 & 1.00 & & & \\
第3因子 (有能性) & 0.54 & -0.01 & 1.00 & & \\
\hline
\end{tabular}

その結果、モデルのデータへの適合に関しては、適合度指標はGFI = 0.94, AGFI = 0.91, CFI = 0.93, RMSEA = 0.06であり、モデルはデータを十分に説明していることが 確認された。全体的に見て、自律性（第1因子）と有能性（第3因子）の因子間相関が 比較的強いことがわかる $(r=0.54)$ 。これは教室における自律的な雾囲気が、学習 者の有能感の認知と強く関係していることを意味する。つまり、このことは教師が生 徒からの要求に柔軟に応えようとしていると生徒が認知すると、生徒の有能感は高 まる可能性があることを示唆するものである。一方、他者との関係性は自律性や有能 性とはほとんど相関がなかった。したがって、対人関係がうまくいっているからといっ て、それが英語学習における自律性の助長や有能感の認知には直接的にはつながら ない可能性が示された。 


\section{動機づけ尺度の分析結果}

動機づけ尺度についても、上記と同様の手順で分析を行った。予備調査から得ら れた15項目すべてを探索的因子分析に利用したところ、想定された 5 因子モデルが採 択された。そのモデルに対して、検証的因子分析を行った。各尺度項目の平均、標準 偏差、探索的因子分析の結果 (パターン行列)、ならびに検証的因子分析の結果（因 子間相関)について表2に示す。

\section{表2:動機づけ尺度に関する探索的因子分析 (パターン行列) と検証的因子分析 (因子間相関)の結果}

\begin{tabular}{|c|c|c|c|c|c|c|c|}
\hline 質問項目 & 外的 & 内発的 & 同一視 & 無動機 & 取り入れ & 共通性 & $\begin{array}{c}\text { 平均 } \\
\text { (標準偏差) }\end{array}$ \\
\hline \multicolumn{8}{|l|}{ 第1因子 $(\alpha=.84)$} \\
\hline 外的1 (そうすることになっているから) & 0.90 & -0.02 & 0.07 & 0.05 & -0.20 & 0.95 & $2.7(1.1)$ \\
\hline 外的2 (それは決まりだから) & 0.82 & -0.01 & -0.09 & -0.01 & 0.02 & 0.74 & $2.7(1.2)$ \\
\hline 外的3 (そうしないと両親に叱られるから) & 0.43 & 0.06 & -0.25 & -0.05 & 0.26 & 0.40 & $2.1(1.1)$ \\
\hline \multicolumn{8}{|l|}{ 第2因子 $(\alpha=.82)$} \\
\hline 内発1 (英語は面白いから) & -0.01 & 0.88 & -0.01 & 0.00 & 0.03 & 0.76 & $3.1(1.1)$ \\
\hline 内発2 (英語は興味をそそるから) & 0.13 & 0.85 & 0.11 & 0.00 & -0.08 & 0.78 & $3.1(1.1)$ \\
\hline 内発3 (英語を勉強するのは趣味だから) & -0.14 & 0.60 & -0.03 & 0.00 & 0.16 & 0.37 & $2.2(1.0)$ \\
\hline \multicolumn{8}{|l|}{$\begin{array}{r}\text { 第3因子 }(\alpha=.81) \\
\end{array}$} \\
\hline 同一視1 (自分の成長にとって役立つから) & -0.01 & -0.05 & 0.77 & -0.11 & -0.01 & 0.62 & $3.5(1.1)$ \\
\hline 同一視2 (1 国語以上話せるようになりたいから) & -0.12 & 0.04 & 0.73 & 0.16 & 0.09 & 0.57 & $3.7(1.1)$ \\
\hline 同一視3 (他の生活場面で役立つから) & 0.01 & 0.11 & 0.69 & -0.09 & 0.01 & 0.61 & $3.5(1.1)$ \\
\hline \multicolumn{8}{|l|}{ 第4因子 $(\alpha=.79)$} \\
\hline 無動機1 (英語の何を勉強してるかわからない) & -0.12 & 0.03 & 0.01 & 0.86 & 0.09 & 0.66 & $2.7(1.1)$ \\
\hline 無動機2 (時間を無駄にしていると思う) & 0.05 & -0.08 & 0.03 & 0.71 & -0.05 & 0.55 & $2.3(1.1)$ \\
\hline 無動機3 (そこから何を得ているかわからない) & 0.19 & 0.05 & -0.08 & 0.61 & 0.00 & 0.55 & $2.5(1.0)$ \\
\hline \multicolumn{8}{|l|}{ 第5因子 $(\alpha=.47)$} \\
\hline 取り入れ1 (勉強しないと気まずいから) & 0.24 & -0.02 & 0.25 & 0.02 & 0.55 & 0.56 & $2.8(1.0)$ \\
\hline 取り入れ2 (勉強しないと心配になるから) & 0.08 & -0.05 & 0.02 & 0.05 & 0.54 & 0.39 & $2.5(1.1)$ \\
\hline 取り入れ3 (他の生徒にできると思わせたいから) & -0.15 & 0.11 & -0.16 & 0.01 & 0.35 & 0.08 & $2.4(1.3)$ \\
\hline 因子間相関 第 1 因子 (外的) & 1.00 & & & & & & \\
\hline 第 2 因子 (内発的) & -0.33 & 1.00 & & & & & \\
\hline 第 3 因子 (同一視) & -0.41 & 0.62 & 1.00 & & & & \\
\hline 第 4 因子 (無動機) & 0.62 & -0.40 & -0.43 & 1.00 & & & \\
\hline 第 5 因子 (取り入れ) & 0.53 & -0.11 & 0.13 & 0.36 & 1.00 & & \\
\hline
\end{tabular}

その結果、モデルのデータへの適合に関しては、適合度指標はGFI = 0.94, AGFI = 0.92, CFI = 0.97, RMSEA = 0.04であり、モデルはデー夕を十分に説明していることが 確認された。全体的に見て、同一視的調整（第3因子）に関する3項目の平均が他の 下位尺度のそれを大きく上回った。したがって、本研究の被調査者にとって、英語学 習というものはとりわけ重要なものとして受容され、その価値を十分に認めた上で学 習に取り組んでいる傾向があると考えられる。

また、因子間相関について、Deci and Ryan (1985) では動機づけの各タイプ間にシ ンプレックス構造を想定している。これは先の図 1 内発的動機づけと同一視的調整）では強い正の相関が得られ、連続体の対極に位置 する概念間 (例えば、内発的動機づけと無動機) では無相関、あるいは強い負の相関 を示すという仮定である。分析によって得られた因子間相関は、例えば内発的動機づ け（第2因子）はそれと概念的に近い同一視的調整（第3因子）と強い正の相関を示し 
$(r=0.62)$ 、対極に位置する無動機（第4因子）とは負の相関を示した $(r=-0.40)$ 。そ の他の因子間相関についても、概ね同様の結果が得られた。したがって、本研究では SDTにおける動機づけは自己決定の程度に基づいて、内発的動機づけ、同一視的調 整、取り入れ的調整、外的調整、無動機という順に連続体を形成しているということ が改めて確認された。

なお、信頼性係数に関しては、全体的に尺度として利用するのに十分な值を得るこ とができたが、第5因子に関しては著しく低い值が得られた $(\alpha=.47)$ 。これは心理 尺度として利用するには内的整合性が低いと考えられる。そのため、第5因子につい ては、各項目間の相関係数を検討した。それを表3に示す。

\section{表3:第5因子 (取り入れ的調整) の項目間相関}

\begin{tabular}{lccc}
\hline \multicolumn{1}{c}{ 質問項目 } & 取り入れ1 & 取り入れ2 & 取り入れ3 \\
\hline 取り入れ1:勉強しないと気まずいから & 1.00 & & \\
取り入れ2: 勉強しないと心配になるから & $.46^{* *}$ & 1.00 & \\
取り入れ3: 他の生徒にできると思わせたいから & .07 & $.21^{* *}$ & 1.00 \\
\hline
\end{tabular}

$* * p<.01$

その結果、「他の生徒にできると思わせたいから」という項目が内的整合性を低め ていることが示唆された。したがって、第5因子については項目の更なる検討が必要 であると判断したため、以下の分析では取り扱わないこととした。

\section{英語学習における心理的欲求と動機づけの因果モデル}

最後に、心理的欲求が動機づけの各タイプに及ぼす影響について検討するため、 構造方程式モデリングが行なわれた。分析は Amos 4.0を用い、最尤法を母数の推定 法とした。ここでは各項目を観測変数として分析を行い、分析後、有意でないパスを削 除し、再度分析が行われた。因果モデルは、Deci and Ryan (1985)、Vallerand (1997) などに基づき、動機づけの各タイプに対して3つの心理的欲求がそれぞれ影響を及ぼ し、さらに自律性と有能性は共変動するものとして想定された。分析の結果について は、図2に示された通りである。

このモデルの最終的な適合度指標はGFI $=0.90, \mathrm{AGFI}=0.88, \mathrm{CFI}=0.94, \mathrm{RMSEA}$ $=0.04$ であり、モデルとデー夕の適合はよいことが確認された。

以下では、モデルからわかることを3つの観点から述べる。1点目は有能性の認知 が動機づけに対して強く影響を与えているということである (有能性から内発的動 機づけ、同一視的調整、外的調整、無動機への因果係数は、それぞれ .40, .34，-.23, -.34）。White（1959）は、環境を思い通りに変えたり操作したりできるという効力感が 内発的動機づけの中核であると主張している。学習に対して成功経験や肯定的評価 が与えられる学習者は学習についての有能感を発達させるが、失敗経験や否定的評 価が与えられると学習についての有能感が疎外され、無力感を強めてしまう。したが って、学習においてより望ましい状態とされる内発的動機づけを高めるためには、有 能性の欲求を満たすということが非常に重要だと考えられる。

次に1点目と関連して、内発的動機づけのようなより高い自己決定を実現・保障す るためには、関係性の欲求を満たす必要があるということである (関係性から内発的 動機づけ、同一視的調整への因果係数は、それぞれ.24,.33）。この結果は教室にお 


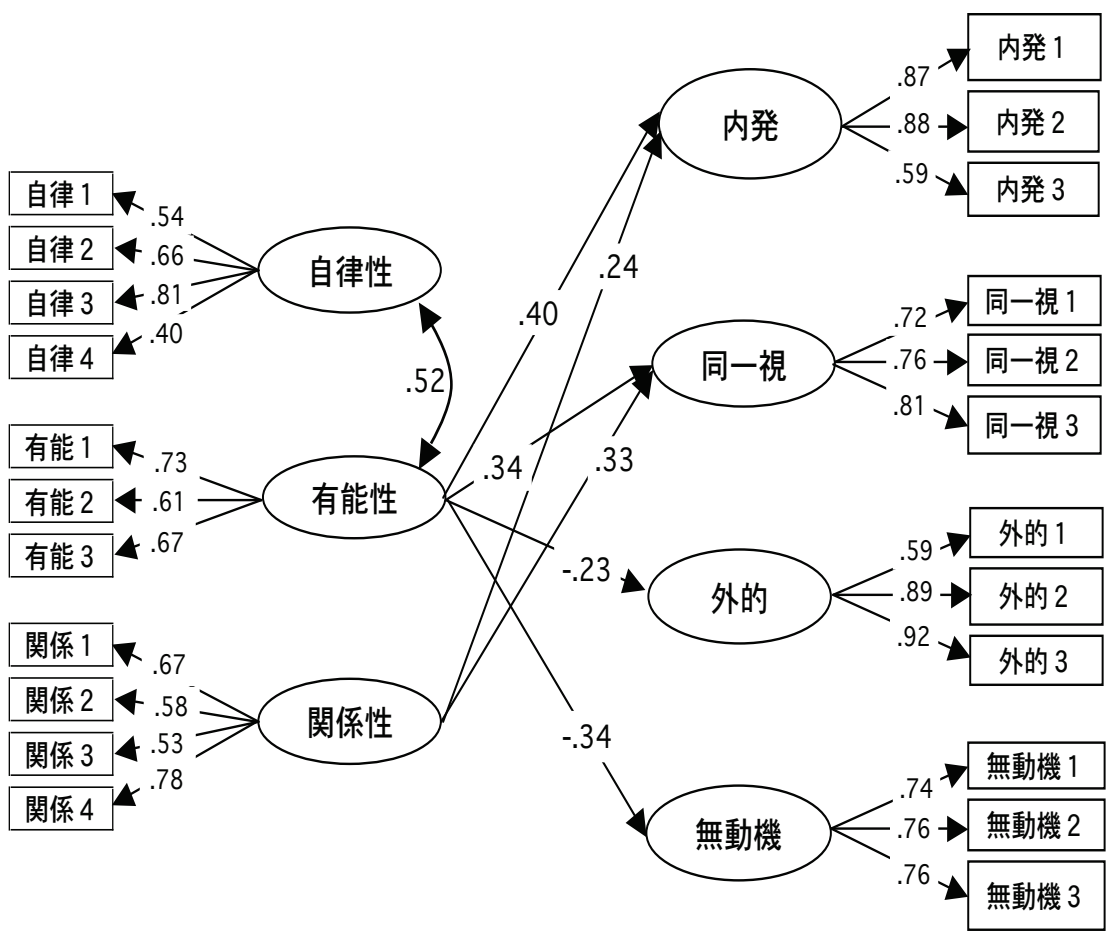

図2: 心理的欲求と動機づけの因果モデル（標準化解による簡略図）

ける英語学習を考える上で、示唆に富むものである。なぜなら、とりわけ高等学校に おける英語学習というものは自学自習的に個別になされることが多く、他者との関わ りについてはあまり問題視されることは少ないように思われる。しかし、英語を外発 的動機づけにより学ぶ傾向が強いと思われる中高生にとっては、たとえ英語を手段 として学習している場合でも、仲のよい友達が英語が得意だったり重要だと感じてい たら、彼らは「自分もやってみよう」「ひょっとしたら、面白いのかもしれない」と感じ るであろう。Deci and Ryan (2002) は外発的に動機づけられた行動であっても、親 密な他者によってその行動が促進され、結果として、その行動の価值を自らの中に内 在化させていくと指摘している。したがって、本研究の結果からも、英語学習の価值 を自らに統合、内化させ、より内発的に動機づけていくためにも、他者との関係性は これまで以上に注目すべき要因であると言える。

3点目は自律性に関してだが、今回の調査では動機づけに対して自律性から有意 なパスが確認されなかった。しかし、この結果は有能性との双方向パスの存在によっ て引き起こされた可能性が高いと考えられる。すなわち、自律性と有能性は互いに密

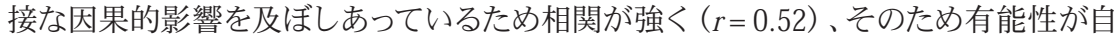
律性の成分を代表してしまったという可能性である。したがって、自律性に関しても、 
直接動機づけに影響を与えなくとも、有能性を介して間接的に影響を与えている可 能性があると言えよう。つまり、教室において自律的な風土を与えることが学習者の 有能感を高め、その結果として彼らの動機づけが高まると考えられる。

\section{教育的示唆}

本研究の結果から、教室での英語学習を進める上でとりわけ有効だと思われる教 授方略について、2つの観点から述べる。1つ目は、本研究の結果からもその重要性が 改めて確認された有能性の欲求に関するものである。学習活動がより発展的になる につれて、学習者が成功する自信をなくしたり失敗を経験するということは必然的な ものとなる。そのような時、教育者はただ単に評価的なフィードバックを与えるのでは なく、学習者の失敗がどこに起因するのかを明らかにし、建設的かつ情報的なフィー ドバックを与えることが重要になると思われる。例えば、どのように困難点を克服して いったらよいのかについて、実際に教育する側がモデルを示してやることなどが考え られる。そのような試みは学習者の問題解決能力を高める上で非常に有効であり、結 果として、学習者の有能感や動機づけを高める重要な方略になると思われる。

2点目として、学習者がもつ特定の動機づけタイプの発達に関する問題が挙げられ る。SDTの枠組みからみた時、教育者は学習者が自己決定の程度が高い動機づけ (つ まり、内発的動機づけ）を持つように支援するだけでなく、個々の学習者が「徐々に」 自ら学ぶ意欲を育て、将来的に学習に対する内発的動機づけを高めていく指導が必 要となる。例えば、英語の教師にとつて、英語を勉強したくない、あるいは英語が嫌い な生徒 (つまり、無動機な生徒) を動機づけるということは非常に骨の折れる仕事で ある。しかし、著者は本稿で述べたように、連続体として動機づけを捉える（無動機 一外的調整一取り入れ的調整一同一視的調整一内発的動機づけ) ことにより、これま で以上により効果的な教育的介入が可能になるものと考える。つまり、教師は連続体 上のより内発的な状態に向けて、学習者を「徐々に」動機づけていくことが出来るもの と考える。

例えば、学習者が英語学習に対して無動機の状態にあったとする。そのような場 合、彼の支配的な動機づけを無動機から外的、あるいは取り入れ的調整に変えてい くためには、彼の能力を教育する側がまず認めてあげることが必要とされるだろう。 しかし、英語学習に対して取り入れ的調整の動機づけをもつ学習者を同一視的調整 へと発達させるためには、学習者に学習自体がもつ重要性を理解させたり、周りの学 習者が学習に対して抱いている肯定的な認識を伝える必要があると思われる。

本研究のように動機づけを連続的に細分化して捉えることは、学習者の個人差に 焦点を当てることを可能とする。つまり、例えば、学習に対して不適応的な動機づけ をもつ学習者を、段階的に適応的な動機づけへと導くにはどうしたらよいかを知る上 で、重要な手がかりを与えるものとなる。したがって、自己決定理論を外国語教育に 応用することは、個々の学習者に対してカウンセリング的なアドバイスを可能にする 上でも、非常に有益だと考える。また、このような視点をもつ研究こそが、実際の教育 現場に還元するに耐えうる研究になるものと考える。

\section{結論}

本研究の第1の目的は、SDTに基づく心理的欲求、動機づけの尺度を日本の英語 教育場面を想定した上で作成し、その適用可能性について検討することであった。探 索的因子分析などを通じて分析した結果、概称信頼性・妥当性ともに十分な尺度の 
開発がなされた。とりわけ、動機づけ尺度に関していえば、因子間相関はほぼシンプ レックス構造を示したことから、日本においてもDeci and Ryan (1985) のモデルは支 持されることが示された。しかし、第5因子 (取り入れ的調整)に関しては今後、項目 の検討等が必要なことが示唆された。

また、各動機づけのタイプの平均を検討すると、同一視的調整の平均の高さが目 を引いた。このことはこれまでの先行研究にも見られる傾向である（速水, 1995）。つ まり、極端な内発的、あるいは外発的動機づけよりも、行動を個人的に重要なものと して受容し、その価值を認めた上で行動を調整している同一視的調整の方が、学習 行動を支える中核的な動機づけになり得ることを示唆している。したがって、今後は この点についてさらに検討を進めていく必要がある。

また、構造方程式モデリングの結果、有能性の認知は動機づけに対して強い影響 力を持っていること、また関係性に関しても内発的動機づけを高める上では重要な 役割を果たしていることが明らかになった。自律性については、有能性を介して動機 づけに間接的に影響するという可能性が示唆された。しかし、近年、自律に対する認 識とそれへの価值の置き方は、文化的背景による差異が認められることが報告され 始めている。例えば、 Iyenger and Lepper（1999）は、西洋文化では通常、「(自ら) 選 択をする」ということが好まれるが、非西洋文化では常にそうとは限らず、時には「(親 しい人に）選択をしてもらう」ということのほうが好まれることがあることを指摘して いる。また、Heine and Lehman (1997) は相互依存性の高い文化圈 (interdependent cultures）の人々は、自ら選択することにあまり拘らないし、自らの選択に対しても強 い肩入れはしないというような研究成果を報告している。

このようなことから、人間は必ずしも選択の自由が与えられる状況（つまり、自律性 の欲求が満たされた状況）を好むとは限らない可能性のあることが示唆される。しか し、SDTでは自律性のような心理的欲求は普遍的なものとして想定されている (Ryan \& Deci, 2002)。したがって今後は、教室における英語学習場面において、このような欲 求は普遍的なものなのか、あるいは文化的背景による差異を考慮すべきかについて、 引き続き検討を行なう必要があると考える。

さらにその他の課題としては、心理的欲求や動機づけと学習成果との関連につい て検討する必要がある。そうすることによって、より実践的示唆に富む研究への発展 が期待できる。また、本研究では動機づけの先行要因として心理的欲求を仮定する というトップダウン的なアプローチを採用したが、学習者の内発的動機づけを高める 要因をより広く探っていくためにも、今後は自由記述調査などから他の動機づけ要因 を明らかにしていくというボトムアップ的なアプローチも必要であろう。

学習者を動機づけるという行為、あるいは現象は、認知的・情意的な総合性を持つ ものである。これまでの研究と異なり、本研究は「何が」学習者の動機づけを高めるの かという、動機づけの先行要因について検討した。このような研究は、教室における英 語教育活動を考える上で、有益な視点を提供するものと考えられる。なぜなら、英語学 習における動機づけ要因の解明は、日常の教室活動において、教育者が学習過程のど の部分に働きかけたらよいのかを知る貴重な情報源となるからである。

\section{筆者略歴}

著者は現在、北海道の公立高校で非常勤講師 (英語) を勤める傍ら、北海道大学 大学院国際広報义ディア研究科 (博士課程) にて研究を行なっている。主な研究の 関心は、第二言語習得における心理学的な側面である。 


\section{参考文献}

Chen, Y-L. (1999). Motivation and language learning strategies in learning English as a foreign language. Unpublished doctoral dissertation, Washington, DC: University of Washington.

Cohen, A.D., \& Dörnyei, Z. (2002). Focus on the language learner: Motivation, styles, and strategies. In N. Schmitt (Ed.), An introduction to applied linguistics (pp. 170-190). London: Arnold.

Crookes, G., \& Schmidt, R.W. (1991). Motivation: Reopening the research agenda. Language Learning, 41, 469-512.

Deci, E.L. (1975). Intrinsic motivation. New York: Plenum.

Deci, E.L., \& Ryan, R.M. (1985). Intrinsic motivation and self-determination in human behavior. New York: Plenum Press.

Deci, E.L. \& Ryan, R.M. (Eds.). (2002). Handbook of self-determination research. Rochester, NY: University of Rochester Press.

Dörnyei, Z. (1990). Conceptualizing motivation in foreign language learning. Language Learning, 40, 45-78.

Dörnyei, Z. (1999). Motivation. In B. Spolsky (Ed.), Concise encyclopedia of educational linguistics (pp. 525-532). Oxford: Pergamon Press.

Ehrman, M.E. (1996). An exploration of adult language learner motivation, selfefficacy and anxiety. In R.L. Oxford (Ed.), Language learning motivation: Pathways to the new century (pp. 81-103). Honolulu: University of Hawai'i Press.

Ellis, R. (1994). The study of second language acquisition. Oxford: Oxford University Press.

Gardner, R.C. (1985). Social psychology and second language learning: The role of attitudes and motivation. London: Edward Arnold.

Gardner, R.C., \& Lambert, W.E. (1972). Attitudes and motivation in second language learning. Rowley, MA: Newbury House.

Gardner, R.C., \& MacIntyre, P.D. (1993). A student's contributions to second language learning. Part II : Affective variables. Language Teaching, 26, 1-11.

Harter, S. (1981). A model of intrinsic mastery motivation in children: Individual differences and developmental change. In W.A. Collins (Ed.), Minnesota symposium on child psychology, 14, (pp. 215-255). Hillsdale, NJ: Erlbaum.

速水敏彦 (1995).「外発と内発の間に位置する達成動機づけ」『心理学評論』38, 171-193.

Heine, S.J., \& Lehman, D.R. (1997). Culture, dissonance, and self-affirmation. Personality and Social Psychology Bulletin, 23, 389-400.

Iyenger, S.S., \& Lepper, M.R. (1999). Rethinking the value of choice: A cultural perspective on intrinsic motivation. Journal of Personality and Social Psychology, 76, 349-366. 
McCombs, B.L. (1998). Integrating metacognition, affect, and motivation in improving teacher education. In N.M. Lambert \& B.L. McCombs (Eds.), How students learn: Reforming schools through learner-centered education (pp. 379-408). Washington, DC: American Psychological Association.

Noels, K.A., Pelletier, L., Clement, R., \& Vallerand, R. (2000). Why are you learning a second language? Motivational orientations and self-determination theory. Language Learning, 50, 57-85.

Oxford, R.L., \& Shearin, J. (1994). Language learning motivation: Expanding the theoretical framework. The Modern Language Journal, 78, 12-28.

Ryan, R.M., \& Deci, E.L. (2000). Self-determination theory and facilitation of intrinsic motivation, social development, and well-being. American Psychologist, 55, 68-78.

Ryan, R. \& Deci, E. (2002). Overview of self-determination theory: An organismic dialectical perspective. In E.L. Deci, \& R.M. Ryan (Eds.), Handbook of selfdetermination research (pp. 3-33). Rochester, NY: University of Rochester Press.

Schmidt, R.W., Boraie, D., \& Kassabgy, O. (1996). Foreign language motivation: Internal structure and external connections. In R.L. Oxford (Ed.), Language learning motivation: Pathways to the new century (pp. 9-70). Honolulu: University of Hawai'i Press.

Tachibana, Y., Matsukawa, R., \& Zhong, Q.X. (1996). Attitudes and motivation for learning English: A cross-national comparison of Japanese and Chinese high school students. Psychological Reports, 79, 691-700.

Vallerand, R.J. (1997). Toward a hierarchical model of intrinsic and extrinsic motivation. Advances in Experimental Social Psychology, 29, 271-360.

White, R.W. (1959). Motivation reconsidered: The concept of competence. Psychological Review, 66, 297-333.

山森光陽、磯田貴道、廣森友人、田辺洋二 (2002).「研究者のための “motivation theory”から教育者のための “motivating theory”へ: 動機づけ研究を実践に 生かす3つの視点（シンポジウム）」『大学英語教育学会第41回全国大会要 綱』191-192.

\section{謝辞}

本稿を作成するに当たり、2名の匿名査読者の方々には有益なコメントをいただき ました。ここに記して、感謝申し上げます。また、予備調査、ならびに本調査にご協力 くださった高校生の皆様に、心よりお礼申し上げます。 